\title{
CIRCULATORY FAILURE DUE TO VITAMIN B DEFICIENCY
}

\author{
BY
}

\section{A. SCHOTT}

Received December 14, 1943

Cases of cardiac failure due to deficiency in vitamin B1 have been recognized in this country, and although the number of reported cases is small, their recognition is important since treatment by adequate doses of vitamin B1 is rapidly effective, whereas the usual methods of treatment fail. Most cases so far reported occurred in patients drinking too much alcohol and living on an inadequate diet, but a few were caused by deficient diet alone. Observations on three cases of "avitaminosis-B1 heart" showed some unusual features which seem to justify a communication. Two of the three drank too much alcohol, but in the remaining one the condition was caused solely by deficient diet.

\section{CASE RePorts}

Case 1. A man, aged 42, was referred to me on October 25, 1939, because of a dry irritative cough of two months' duration, the bouts of coughing being precipitated by exertion and often terminated by vomiting. Other complaints were general weakness, especially in the legs, and shortness of breath, even on walking slowly on the level. Latterly intermittent swellings had occurred in various parts, especially in the face, legs, and penis; such swellings developed rather quickly, in the course of a few hours, lasted for varying periods of time, and subsided again in the course of a few hours. $\mathrm{He}$ " had always drunk too much," chiefly port, cheap wine, and some beer; his appetite had steadily deteriorated: a small breakfast was his only solid meal and this he often vomited.

On examination, he had a hacking, brassy cough, reminiscent of the type met in cases of mediastinal tumour or aortic aneurysm. The face was puffy and pale, and the left mandibular region was diffusely swollen. The right lobe of the thyroid was slightly enlarged. There was a regular tachycardia of 98, a short systolic murmur over the apex, and a few fine crepitations over the right base. The blood pressure was $130 / 85$. The lower border of the liver was just palpable on deep inspiration. On the right calf were three shallow ulcers. Radiologically the heart was much enlarged to the right and left; the normal concavity on the left border was absent and the region of the pulmonary conus was slightly prominent. Hæmoglobin, 70 per cent. There was no œdema of the legs or genital organs, but when seen one week later there was marked œdema of the penis, which according to the patient had come on in the course of a few hours; there was also slight odema of the ankles. An electrocardiogram (Fig. 1A) showed șinus tachycardia, rate 98. The main deflections in all three limb leads were directed upwards and there was a small S I and a small Q III. The T waves in lead I and the left pectoral chest lead were very wide, shallow and upright and had a dome-like appearance with their convexity directed upwards, originating in the iso-electric line in lead I and slightly $(1.5 \mathrm{~mm})$ above it in the chest lead; there was no high take-off. T II was almost absent and T III inverted. The duration of the electrical systole (Q-T interval) was greatly increased. It is always related to the heart rate and using the formula most commonly employed: $Q-T=K \cdot \sqrt{\text { length of cycle, }}, \mathrm{K}$ (calculated in lead $\mathrm{I}$ ) was found to be 0.49 (upper limit of normal 0.43 according to Shipley and Hallaran, 1936); the duration of $\mathrm{Q}-\mathrm{T}$ was also considerably outside the normal limits of the diagram worked out by Hegglin and Holzmann (1937) to show graphically the range of normal Q-T intervals with different heart rates.

The patient was put on vitamin B1 (Betaxan, $25 \mathrm{mg}$. by injection, daily for 4 days, and later once a week, in all 7 injections, also $20 \mathrm{mg}$. by mouth daily), and when seen again on November 15 his condition had improved. The swellings, cough, and crepitations had disappeared and the dyspnoea was considerably less. He had lost $17 \mathrm{lb}$. in three weeks. The heart shadow had decreased in size. Fig. 1B showed conspicuous changes as compared with Fig. 1A: R I had increased in height and the main deflections in lead III were now directed downwards and grossly slurred; T I had become inverted and T III upright, the R-T in lead I was curved, with the convexity directed upwards. The duration of the electrical systole had further increased, $\mathrm{K}$ being $\mathbf{0} 50$. Altogether the tracing showed features most commonly seen in cases of coronary disease. When seen again on December 8 the patient felt fit, and apart from the ulcers on his leg which had not quite healed, all his symptoms and 

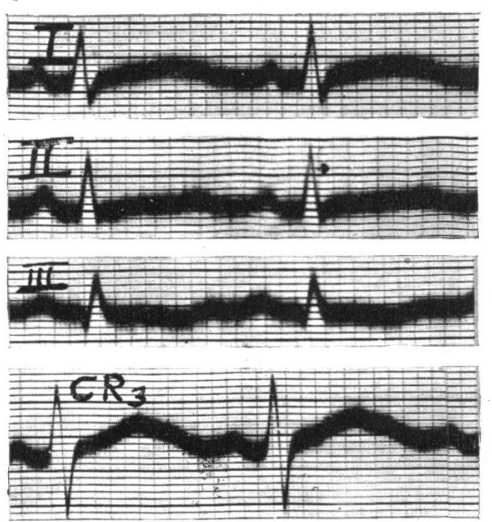

A
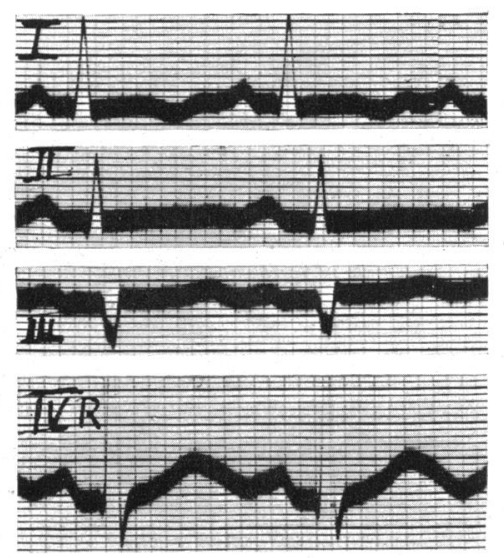
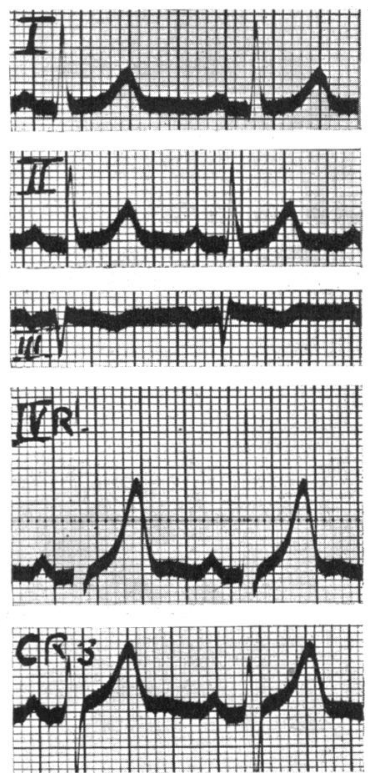

C

Fig. 1.-Case 1. (A) Oct. 25, 1939; (B) Nov. 15, 1939; (C) Aug. 23, 1940. Time markings in (A) and (B) $1 / 25 \mathrm{sec}$, in (C) $1 / 25$ and $1 / 5 \mathrm{sec}$. In this and the subsequent figures: I, II, III, limb leads; IVR, right arm-apex; $\mathrm{CR}_{3}$, right arm-fourth left intercostal space midway between left border of sternum and midclavicular line. For description of changes, see text.

signs had disappeared. A cardiogram showed a rate of $92 ; \mathbf{R}$ II had become higher and small $\mathbf{R}$ waves had appeared in lead III; T I and T II were upright and normal in shape, measuring 3 and $2.5 \mathrm{~mm}$. respectively; T III had decreased in height to $0.5 \mathrm{~mm}$. The chest lead (apical) was normal. The duration of the electrical systole had considerably decreased, $\mathrm{K}$ being $\mathbf{0 . 4 6}$. The patient felt well until March, 1940, when he started to drink again heavily. He discontinued vitamin B1 in June, 1940, but took halibut liver oil and malt, and when seen again in August, 1940, complained of a continuous feeling of anxiety and slight œedema of the ankles. A cardiogram (Fig. 1C) was normal in all leads, showing some left axis deviation; the rate had decreased to 71-77. The duration of the electrical systole had become normal, $\mathrm{K}$ being $\mathbf{0 . 4 2}$. Subsequently, the patient discontinued all treatment in spite of drinking even more heavily. When seen again in October, 1940, his general condition had deteriorated, with increased feeling of anxiety, morning sickness, some cough and occasional paræsthesiæ in the ankles, but swellings had not recurred and the cardiogram was unchanged.

Case 2. A man, aged 62 (in 1942), had been under periodical observation since 1922 for moderate emphysema of the lungs and atherosclerosis, which were very slowly progressing. Apart from slight dyspnœa on exertion, his condition did not give rise to any complaint. There was also a congenital neurological lesion diagnosed by a neurologist as forme fruste of Little's disease. Apart from very occasional dysphasia and ocular disturbances, he was free from complaints and the condition had remained stationary all his life. A cardiogram in 1937 (Fig. 2A) showed sinus rhythm, rate 64; there was left axis deviation with notching of S III. T I and T II were flat but upright, the S-T intervals in lead I were normal and in lead II slightly $(<1 \mathrm{~mm}$.) depressed below the iso-electric line; the chest lead (left pectoral) was normal. The main physical findings in 1939 were the signs of moderate emphysema of the lungs, a long systolic murmur over the apex, some rise in blood pressure $(170 / 100)$ and bilateral extensor plantar reflexes.

The patient had always taken a fair amount of whisky, but while being on a full diet did not show any signs of alcoholism or vitamin deficiency. In the autumn of 1941, however, he increased his consumption of alcohol to an average of three-quarters of a bottle a day and lived almost exclusively on carbohydrates (Ovaltine and milk puddings). When seen on February 7, 1942, he was so weak that he was unable to turn over in bed, and to sit up slowly in bed with assistance constituted a maximum effort. There was marked dyspnoea, disproportionately aggravated by talking and moving, and anorexia. A purpuric rash covered both legs and there was marked muscular fibrillation in the calves, thighs, and arms and to a lesser extent on the abdomen. The calves were tender. There was a mild conjunctivitis. The lower border of the liver was now palpable about two fingers' breadth below the costal margin. The blood pressure had dropped to $125 / 65$. The neurological findings were unchanged with the exception of the ankle jerks which were no longer obtainable. Al about the same time he started a moderate periodical pyrexia which proved to be due to an infection with Brucella melitensis. Hæmoglobin, 66 per cent. Urine normal. Fig. 2B showed significant changes 


\section{CIRCULATORY FAILURE DUE TO VITAMIN B DEFICIENCY}

compared with the record taken in 1937 (Fig. 2A). There was sinus rhythm, rate 75 . The initial ventricular deflections in the limb leads were considerably smaller and in lead III were directed upwards. The R-T intervals had become deformed and curved with their convexity directed upwards and in leads II and III and in the chest leads were depressed below the iso-electric line. T I had become flatter and in the remaining leads diphasic. Altogether the tracing exhibited features indicative of myocardial damage.

The patient was put on vitamin B1 injections, $10 \mathrm{mg}$. daily, also vitamin B1 by mouth, later supplemented by other vitamins (Medikap tablets 4 daily and Redoxon $50 \mathrm{mg}$. daily, the former being replaced later by Benerva compound tablets, 6 daily), iron (Fersolate, 6 tablets a day) and coramine (15-20 drops t.i.d.). He regained some strength very quickly, and when seen again after four days could easily turn over in bed, dyspnœa and appetite had considerably improved. The conjunctivitis
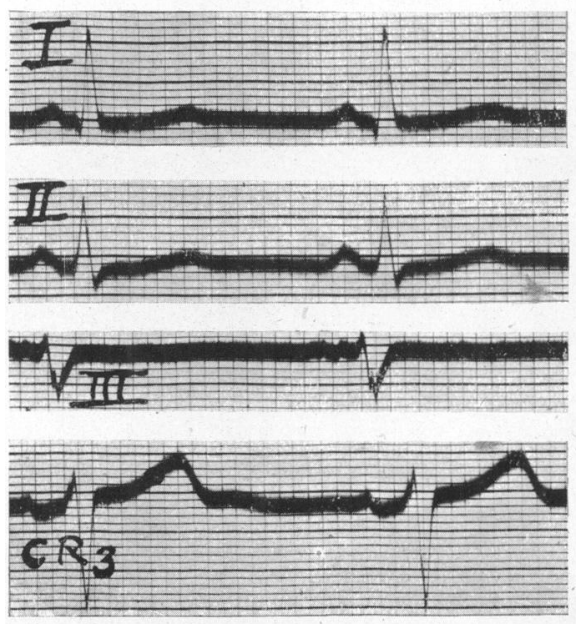

A
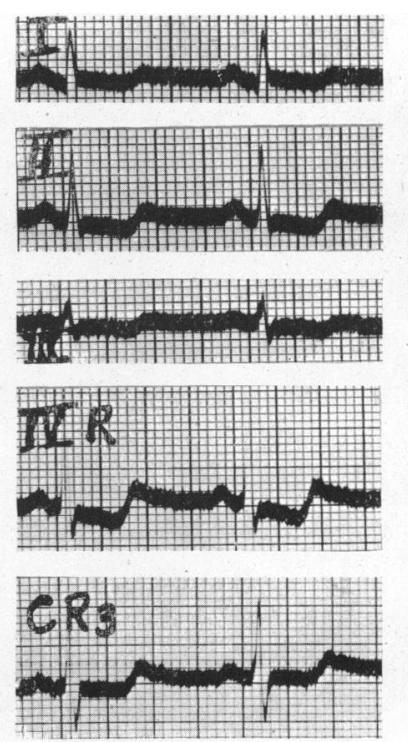

B
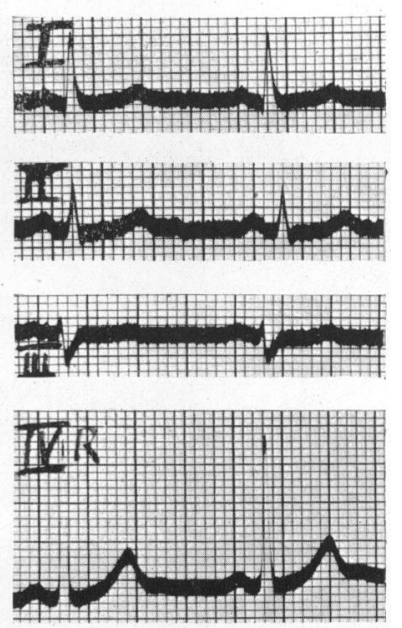

C

Fig. 2.--Case 2. (A) Aug. 17, 1937; (B) Feb. 7, 1942; (C) Feb. 22, 1942. Time markings: in (A) 1/25 sec. in (B) and (C) $1 / 25$ and $1 / 5 \mathrm{sec}$.

had disappeared and the purpuric rash was fading. The muscular fibrillation, however, had increased in intensity and extent ; it improved only very slowly, disappearing after six months, and the Brucella infection took about eight months to clear up. The blood count improved steadily. The further convalescence was complicated by a thrombophlebitis in the right leg. The blood pressure remained low for a year, but reached 150/80 in April, 1943, and remained at that figure.

An electrocardiogram taken on the fourth day of vitamin treatment showed that the changes in the R-T portions described above had already become less marked, particularly in leads II and III; R I had increased and R III decreased in height; the rate had decreased to 70 . After another 11 days of vitamin treatment Fig. 2C showed essentially the same features as the record taken in 1937 before the onset of vitamin deficiency (Fig. 2A), only that there was now a small upright T III; otherwise the signs of myocardial disease had disappeared although the Brucella infection was active throughout that period and on the evening before Fig. $2 \mathrm{C}$ was recorded the temperature had been 101.8. This observation illustrates that the electrocardiographic changes were specifically due to the vitamin deficiency. Accurate measurements of the duration of the electrical systole were not possible in this case.

Case 3. A man, aged 51. Admitted to Guy's Hospital on July 6, 1943, because of swelling of both legs and thighs, attacks of giddiness with collapse on several occasions and shortness of breath on exertion. The condition had started three months before admission and had gradually become worse. He had been out of regular work for ten years and had lived a precarious life as a tramp, having various occupations, some of which entailed much physical exertion, and he had long periods of malnutrition, usually living on tea, bread, butter, margarine, and jam, which he obtained at coffee stalls. He did not take any alcohol.

On examination he looked frail ; the skin had a slight yellowish tinge. The calves were very tender and there was œdema of both legs and thighs. The abdomen was distended and there was ascites; rales were heard over both bases. Hæmoglobin, 30 per cent; blood pressure, 140/65. The ankle jerks could not be obtained. There was achlorhydria. He was put on injections of vitamin B1, $5 \mathrm{mg}$. daily, ordinary diet and Blaud's pills and his condition improved rapidly. His urinary output was $35 \mathrm{oz}$. on the first day of vitamin treatment and during the following four days was $689 \mathrm{oz}$. 
The tenderness over the calves and the dyspnœa improved in the course of a fortnight. After a week he developed diarrhœa which stopped when Blaud's pills were discontinued. From July 17, ascorbic acid (50 mg.) as well as vitamin A and D were added. On discharge on August 19 to a convalescent home he was free from symptoms.

Fig. 3A was taken on the fourth day of vitamin treatment and showed sinus rhythm, rate 87. The initial ventricular deflections in all standard leads were small, R I measuring 5 and $R$ II $4 \mathrm{~mm}$, and

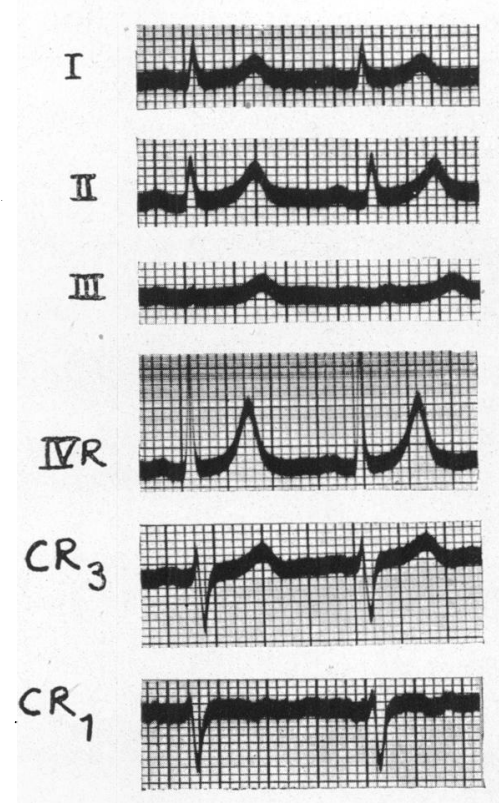

A
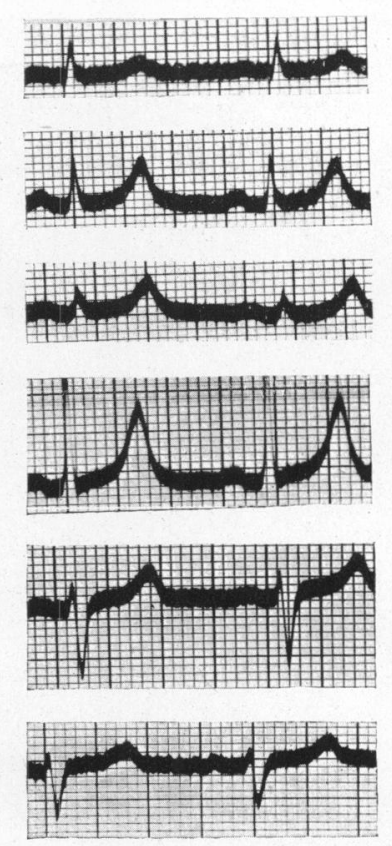
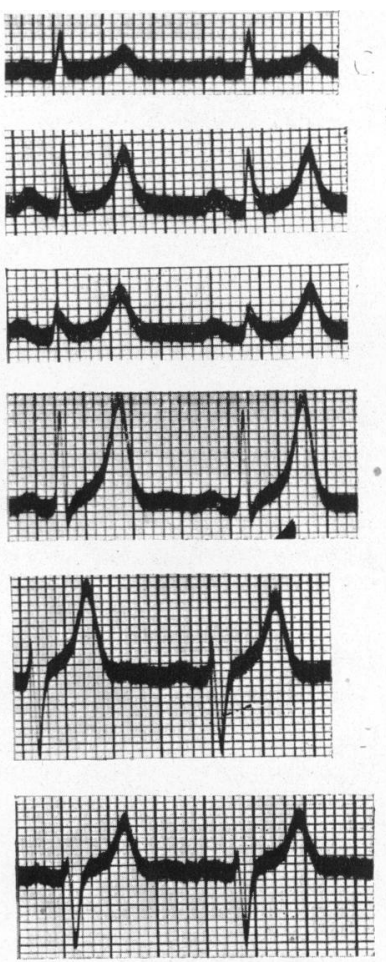

C

Fig. 3.-Case 3. (A) July 10, 1943; (B) July 13, 1943; (C) July 23, 1943. CR : right arm-right border of sternum at the insertion of the fourth rib. Time markings: $1 / 25$ and $1 / 5 \mathrm{sec}$.

R III being almost invisible. In the right pectoral chest lead the $\mathrm{T}$ waves were inverted, otherwise the chest leads were normal. Fig. 3B, taken three days later, showed a rate of 77 and a marked increase in the height of R III and especially of T II and T III; in the right pectoral chest lead the T waves had become upright. Three days later these changes had become more marked, and a week after that there was another conspicuous increase in the height of the T waves in all the leads (except lead I) (Fig. 3C); in lead III and the apical chest lead the height of the T waves exceeded that of the R waves and in lead II they were equal in height. After another week the height of R III and of T II and T III and of the apical chest lead had decreased, and ten days later the record had remained unchanged, except that R III had become almost invisible and there was a small downward deflection instead, measuring less than $0.5 \mathrm{~mm}$. The duration of the electrical systole was within normal limits throughout.

\section{Discussion}

Each of the three cases showed some unusual features of general clinical or cardiological interest.

In Case 1 the outstanding symptoms were weakness, dyspnœa, a dry hacking brassy cough, and transient swellings of unusual distribution. Although a cough of this kind is known to occur in cases of vitamin B1 deficiency (Weiss and Wilkins, 1936, 1937) one does not usually associate it with this condition. Oedema of a similar distribution has been observed by Jones and Bramwell (1939), but is not usually of such transient character. In regard to the electrocardiogram, the $T$ waves in leads $I$ and the chest lead were unusually wide and at the same time flat and "dome-shaped" without a high take-off, the duration of the electrical 
systole being markedly increased. A somewhat similar shape was found by Boyd Campbell and Allison (1940), and Weiss and Wilkins (1936, Fig. 3), but apparently is uncommon. The temporary inversion of the final deflections during the early stages of treatment with vitamin B1 has been reported by several authors (Boyd Campbell and Allison, 1940 ; Dustin Weyler, and Roberts, 1939; Weiss and Wilkins, 1936, 1937). Failure to recognize this as a temporary occurrence during vitamin treatment may result in a mistaken diagnosis of coronary disease, or even recent coronary occlusion. When subsequently the patient had a relapse and several clinical symptoms and signs of vitamin deficiency recurred the electrocardiogram remained normal. These observations are in keeping with the experimental findings of Weiss, Haynes, and Zoll (1938) that in rats fed on a vitamin B1 deficient diet temporary inversion of $\mathrm{T}$ occurred after the injection of vitamin B1 in some animals and that on repeated induction of vitamin B1 deficiency the cardiographic changes were not always identical. In dogs electrocardiographic changes were demonstrated by de Soldati (1940). Lengthening of the duration of the Q-T intervals in cases of vitamin B1 deficiency and a return to normal with adequate treatment was found by several authors (Dustin, Weyler, and Roberts, 1939; Goodhart and Joliffe, 1938; Weiss, 1940; Weiss and Wilkins, 1936, 1937; Dustin, Weyler, and Roberts, 1939), moreover, observed temporary increase at the beginning of treatment.

In Case 2 the onset of signs of vitamin B1 deficiency coincided with the onset of a Brucella infection. It is known that infections not infrequently precipitate the signs of beriberi which until then had remained latent (Aalsmeer and Wenckebach, 1929; Weiss, 1940). In the present case several factors known to precipitate the clinical manifestations of vitamin deficiency co-existed: a negligible intake of vitamin B1 due to gross dietary deficiency, and a high demand of this vitamin owing to the disproportionate amount of carbohydrate in the diet, the excessive consumption of alcohol, and the infection. Gross muscular fibrillation was a prominent sign and it is difficult to decide whether this was due to the vitamin deficiency, the Brucella infection, or the combination of the two. It disappeared after about six months of continual vitamin treatment, about two months before the last manifestation of the Brucella infection. Another conspicuous feature was marked dyspnœa at rest disproportionately aggravated by the slightest physical exertion. The circulatory factors responsible for this condition have been studied in detail by Hayasaki and Inawashiro (1928).

In Case 3 cardiac failure due to vitamin B1 deficiency occurred in a patient who did not take any alcohol, as a result of deficient diet only. Few such cases have been reported in this country (Konstam and Sinclair, 1940; Swan and Lewis, 1940; result of deficient absorption, Ungley, 1939). Physical exertion seems to have precipitated the onset; the importance of this factor is shown by the fact that cardiac failure is less likely to develop or is delayed in its onset in beriberi patients with paralysis (Keefer, 1930), and that severe polyneuritis is usually associated with only a mild degree of congestive circulatory failure (Weiss, 1940). Similar observations have also been made in experimental animals (Swank and Bessey, 1942; Swank, Porter, and Yeomans, 1941). The electrocardiographic findings in Case 3 resemble those of Katz (1941, Fig. 210), especially in respect of temporary gross increase in the height of the $T$ waves in the chest lead.

It is noteworthy that in all three cases the chest leads showed changes, whereas in a series of six cases Dustin, Weyler, and Roberts (1939), found that the chest lead generally showed little disturbance. Changes in the chest leads seem to be more common in pellagra (Feil, 1936).

\section{SUMMARY}

Three cases of circulatory disturbances due to vitamin B1 deficiency are described with special reference to some unusual clinical and electrocardiographic features. Two of the three patients took an excessive amount of alcohol, in the third case the condition was caused by deficient diet only. All responded to treatment with vitamin B1. 
I wish to thank Dr. Geoffrey Marshall, under whose charge Case 3 was admitted to Guy's Hospital, for his permission to examine this patient and publish his notes.

\section{REFERENCES}

Aalsmeer, W. C., and Wenckebach, K. F. (1929). Wien Arch. inn. Med., 16, 193.

Boyd Campbell, S. B., and Allison, R. S. (1940). Lancet, i, 738.

Dustin, C. C., Weyler, H., and Roberts, C. P. (1939). New Engl. J. Med., 220, 15.

Feil, 'H. (1936). Amer. Heart J., 11, 173.

Goodhart, R., and Joliffe, N. (1938). Ibid., 15, 569.

Hayasaka, E., and Inawashiro, R. (1928). Tohoku J. Exp. Med., 12, 29.

Hegglin, R., and Holzmann, M. (1937). Z. klin. Med., 132, 1.

Jones, A. M., and Bramwell, C. (1939). Brit. Heart J., 1, 187.

Katz, L. N., Electrocardiography. London, H. Kimpton, 1941.

Keefer, C. S. (1930). Arch. intern. Med., 45, 1.

Konstam, G., and Sinclair, H. M. (1940). Brit. Heart J., 2, 231.

Shipley, R. A., and Hallaran, W. R. (1936). Amer. Heart J., 11, 325.

de Soldati, L. (1940). Gpt. rend. Soc. Biol., 133, 323. Los trastornos circulatorios en la Avitaminosis B 1. Buenos Aires, El Ateneo, 1940.

Swan, W. G. A., and Lewis, F. (1940). Brit. Heart J., 2, 241.

Swank, R. L., and Bessey, O. A. (1942). Arch. intern. Med., 70, 763.

Swank, R. L., Porter, R. R., and Yeomans, A. (1941). . Amer. Heart J., 22, 154.

Ungley, C. C. (1939). Newcastle med. J., 19, 43.

Weiss, S. (1940). J. Amer. med. Ass., 115, 832.

Weiss, S., Haynes, F. W., and Zoll, O. M. (1938). Amer. Heart J., 15, 206.

Weiss, S., and Wilkins, R. W. (1936). Trans. Ass. Amer. Phys., 51, 341. (1937). Ann. intern. Med., 11, 104. 